\title{
Pressure Transient Analysis by Using MS. Excel Sheet and Computer Programming
}

\author{
Essa M. Tabar*, Ali Omran Nasar, Tariq Basher \\ Petroleum Engineering Department, Engineering Faculty, Sirte University, Libya \\ DOI: https://doi.org/10.21467/proceedings.2.36 \\ * Corresponding author email: etabare4@gmail.com
}

\begin{abstract}
Paper shows an effective using of two programs (MS Excel and computer programming) to analysis the pressure build up test data. The programs were used to determine the best infinite-reservoir acting by the relationship which between the shut-in pressure and logarithm of the shut-in time. The purpose of well test analysis is to identify the type of reservoir involved and to determine the parameters of the reservoir quantitatively. Data from one well, has been analyzed by application of modern well-test analysis techniques, such as derivative analysis and computer programming, in addition to the conventional $\log -\log$ and semi-log methods, and then double check by using Type curve matching. MS Excel sheet and computer programming are using to identify: Wellbore storage effect, Middle time region " straight line", Late time region " boundary effect", and then calculate the permeability and skin factor. The results of two programs shows that the well is located near a sealing fault. Hence, they indicate that Horner method is the most accurate than derivative methods.
\end{abstract}

Keywords: buildup test, pressure transient, derivative method, skin factor, permeability

\section{Introduction}

The pressure build up test is conducted by producing a well at constant rate for some time, shutting the well in, allowing the pressure to buildup in the wellbore, and recording the pressure in the wellbore as a function of time. From these data, it is possible to estimate formation permeability and current drainage-area pressure, and to characterize damage or stimulation and reservoir heterogeneities or boundaries. The method used to analyze the pressure buildup tests can be classified into three main groups; conventional methods (Horner and $\mathrm{MDH}$ ), pressure derivative in 1983 [1]., and then double check by sing type curve matching methods. This paper present analysis of one field cases of the pressure build up test using MS Excel and computer programing (PT4).

(C) 2018 Copyright held by the author(s). Published by AIJR Publisher in Proceedings of First Conference for Engineering Sciences and Technology (CEST-2018), September 25-27, 2018, vol. 1.

This is an open access article under Creative Commons Attribution-NonCommercial 4.0 International (CC BY-NC 4.0)

AiR license, which permits any non-commercial use, distribution, adaptation, and reproduction in any medium, as long as the original work is properly cited. ISBN: 978-81-936820-5-0 
During the last decade, the theory and application of pressure transient testing has tremendous improvements, and many solutions and techniques have been proposed to analysis variety of reservoirs .The purpose of analyzing well test, and production data is to determine the ability of a formation to produce reservoir fluids, where needed to do this by estimating formation properties from reservoir data. Some of the relevant properties that must be determined are permeability, skin effect, and initial reservoir pressure, in general, characterization or description of the reservoir-well system in order to evaluate well damage or stimulation, fracturing or not of the well, the existence of faults or flow barriers, the approximate shape of the drainage area of the reservoir or the change of the reservoir lithological properties [2].

For analysis purpose, pressure drawdown and build-up test data are usually separated into three regions which represent different analysis, and interpretation scenarios. The "early time region" is typically affected by wellbore storage while "middle time "region is indicative of the characteristics of the reservoir itself (transient flow), and finally, the "late time region" pertains to data affected by reservoir boundaries. A typical pressure test may not contain all three regions. It is important to note that the reservoir properties calculated from both build-up and drawdown tests represent average properties within that drainage area.

There are many graphical techniques that can be used to analyze well test data; these techniques include Cartesian, semi-log, and log-log plots of pressure and pressure drop function as shown in Figure (1). The particular analysis technique to be used depends uniquely on the reservoir to be tested. In the fact, it is important to use the $\log$ - $\log$ plot first, as an excellent diagnostic tool to identify the regions of the flow in a reservoir.

The objective of this paper to describe the reservoir well system and determine some reservoir properties for the given well by using different methods, these methods are the conventional method (Horner \& MDH), derivative method. MS Excel sheet and PT4.0 program were used to evaluate this well. The analysis was used for one well in a Libyan field. The pressure of buildup data is shown in Figure 2. Properties of the well and formation are given in Table 1 

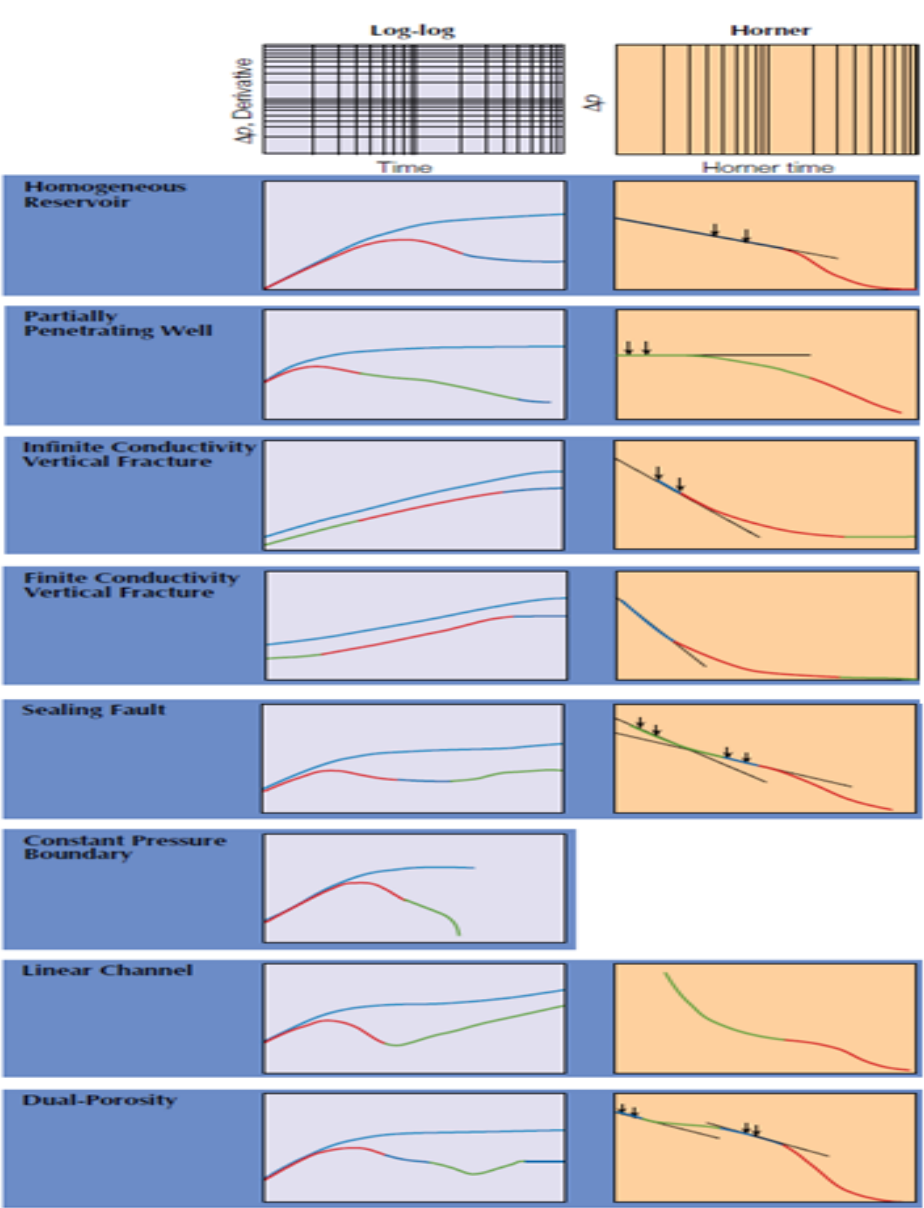

Figure 1: Log-log and semi-log plots for common reservoir systems.

Table 1: Properties of the well and formation

\begin{tabular}{|c|c|}
\hline Property & Value \\
\hline $\mathrm{q}_{\mathrm{o}}(\mathrm{STB} / \mathrm{D})$ & 3540 \\
\hline$\Phi($ fraction $)$ & 0.171 \\
\hline$\mu_{\mathrm{o}}(\mathrm{cp})$ & 0.75 \\
\hline $\mathrm{C}_{\mathrm{t}}\left(\mathrm{psi}^{-1}\right)$ & $1.27 \mathrm{E}-05$ \\
\hline $\mathrm{r}_{\mathrm{w}}(\mathrm{ft})$ & 0.354 \\
\hline $\mathrm{h}(\mathrm{ft})$ & 45.75 \\
\hline $\mathrm{B}_{\mathrm{o}}(\mathrm{RB} / \mathrm{STB})$ & 1.3 \\
\hline $\mathrm{P}_{\mathrm{wf}}(\mathrm{psia})$ & 3346.50 \\
\hline $\mathrm{t}_{\mathrm{p}}$ (hours) & 12.5 \\
\hline
\end{tabular}


Tabar et al., CEST-2018, AIJR Proceedings 2, pp.310-322, 2018

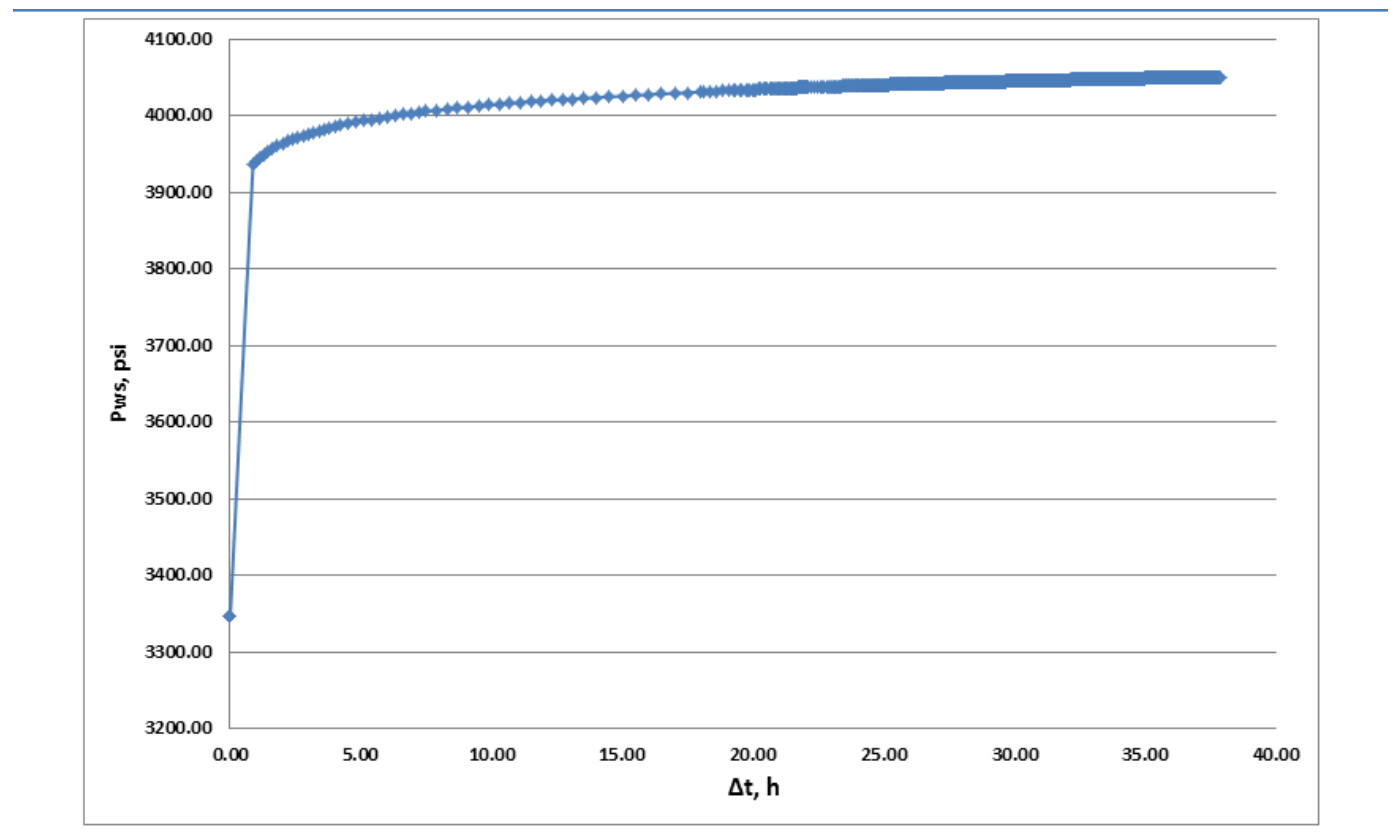

Figure 2: Pressure buildup of the well

\section{Theories of Methods Used}

\subsection{Horner Method}

Combining the law of conversation of mass and Darcy's law for the isothermal radial flow of fluid of small and constant compressibility toward a well in a circular reservoir, results a partial differential equation which called the Diffusivity Equation [3].

$$
\frac{d^{2} P}{d r^{2}}+\frac{1}{r} \frac{d p}{d r}=\frac{\phi \mu C_{t}}{0.000264 k} \frac{d p}{d t}
$$

Assuming that:

1. A well produce at a constant rate,

2. The reservoir is at uniform pressure, $\mathrm{Pi}$, before production begins, and

3. The well drains an infinite area.

Solution of Eq.(1) is:

$$
P=P_{i}+70.6 \frac{q \beta \mu}{k h} E_{i}\left(\frac{-948 \phi \mu C_{t} r^{2}}{k t}\right)
$$

Where:

$\mathrm{B}=$ Formation volume factor, res vol./surface vol 
Pressure Transient Analysis by Using MS. Excel Sheet and Computer Programming

$\mathrm{C}_{\mathrm{t}}=$ Total compressibility, $\mathrm{psi}^{-1}$

$\mathrm{Ei}=$ Exponential wellbore storage coefficient

$\mathrm{h}=$ Net formation thickness, $\mathrm{ft}$.

$\mathrm{k}=$ Reservoir rock permeability, $\mathrm{md}$

$\mathrm{P}=$ Reservoir pressure, psi.

$\mathrm{P}_{\mathrm{i}}=$ Initial reservoir pressure, $\mathrm{psi}$.

$\mathrm{q}=$ Flow rate, $\mathrm{STB} / \mathrm{D}$

$\mathrm{r}=$ Distance from center of wellbore, $\mathrm{ft}$

$\mathrm{t}$ = Elapsed time, $\mathrm{h}$

$\mu=$ Viscosity, cp.

$\varnothing=$ Porosity of reservoir rock, dimensionless.

$E_{i}(-x)=-\int_{x}^{\infty} \frac{e^{-u}}{u} d u=$ the Ei function or exponentia 1

For $\mathrm{x}<0.02$, Ei $(-\mathrm{x})$ can be approximated with an error less than $0.6 \%$ by $\operatorname{Ei}(-x)=$ $\ln (1.781 x)$

For $r=r_{w}$ the argument of the Ei function is sufficiently small after a short time that we can use the logarithmic approximation, thus, the is:

$$
P_{i}-P_{w f}=-70.6 \frac{q \beta \mu}{k h}\left[\ln \left(\frac{1688 \phi \mu C_{t} r_{w}^{2}}{k t}\right)\right]
$$

It is convenient to define a skin factor, $\mathrm{S}$, in term of the properties of the equivalent altered zone:

$$
S=\left(\frac{k}{k_{s}}-1\right) \ln \left(\frac{r_{s}}{r_{w}}\right)
$$

Where:

$\mathrm{k}_{\mathrm{s}}=$ Permeability of altered zone, $\mathrm{md}$

$\mathrm{r}_{\mathrm{s}}=$ Radius of altered zone (skin effect), $\mathrm{ft}$

$\mathrm{r}_{\mathrm{w}}=$ Wellbore radius, $\mathrm{ft}$

$\mathrm{S}=$ Skin factor, dimensionless.

For buildup test using principle of the superposition for well has produced for time at flow rate (q) before shut-in, and if we call time elapsed since shut-in $\Delta t$, the pressure drop can be modeled by Eq 5 . 


$$
P_{i}-P_{w s}=-70.6 \frac{q \beta \mu}{k h}\left[\ln \left(\frac{1688 \phi \mu C_{t} r_{w}^{2}}{k\left(t_{p}+\Delta t\right)}\right)-2 s\right]-70.6 \frac{(-q) \beta \mu}{k h}\left[\ln \left(\frac{1688 \phi \mu C_{t} r_{w}^{2}}{k \Delta t}\right)-2 s\right]
$$

Where:

$t_{\mathrm{p}}$ : Cumulative production $/$ most recent production rate $=$ pseudo producing rate, $\mathrm{h}$

$\Delta \mathrm{t} \quad$ : Time elapsed since shut-in, $\mathrm{h}$.

and become:

$$
P_{w s}=P_{i}+70.6 \frac{q \beta \mu}{k h} \ln \left[\left(\frac{t_{p}+\Delta t}{\Delta t}\right)\right]
$$

or

$$
P_{w s}=P_{i}+162.6 \frac{q \beta \mu}{k h} \log \left[\left(\frac{t_{p}+\Delta t}{\Delta t}\right)\right]
$$

The form of Eq 6b suggests that shut-in BHP, Pws recorded during a pressure build up test should plot as straight line function of $\log [(\mathrm{tp}+\Delta \mathrm{t}) / \Delta \mathrm{t}]$. Further, the slope of $(m)$ of this straight line should be: $m=-162.6 \frac{q \beta \mu}{k h}$

It is convenient to use a positive number of $(m)$ as following Equation.

$$
m=162.6 \frac{q \beta \mu}{k h}
$$

Eq 8 uses to calculate formation permeability, $k$, which can be determined from a buildup test by measuring the slope $m$. in addition, the extrapolation of straight line to infinite shut-in time $\left(\frac{t_{p}+\Delta t}{\Delta t}\right)=1$ the pressure at this time will be original formation pressure, Pi.

$$
k=162.6 \frac{q \beta \mu}{m h}
$$

The skin factor is obtained from Eq 9.

$$
s=1.151\left[\left(\frac{p_{1 h r}-p_{w f}}{m}\right)-\log \left(\frac{k}{\phi \mu c_{t} r_{w}^{2}}\right)+3.23\right]
$$


Pressure Transient Analysis by Using MS. Excel Sheet and Computer Programming

Where:

Pwf $=$ Flowing BHP, psi

$\mathrm{P}_{1 \mathrm{hr}}=$ Pressure at 1-hour shut-in time on middle time-line, psi.

\subsection{Derivative method.}

Five-point method was used to estimate the derivative pressure as shown in Figure 3. The following procedure used to identify the flow regimes in this study:

- Plot pressure derivative versus time on log-log plot (Diagnostic Plot).

- Identify the end of wellbore storage from unit slope line.

- Identify middle time region when zero slope straight line appears.

- Identify the late time region if there is boundary effects.

$$
\begin{aligned}
& m_{L}=\frac{\Delta p_{L}}{\Delta t_{L}} \quad m_{R}=\frac{\Delta p_{R}}{\Delta t_{R}} \\
& \Delta p^{\prime}=\frac{m_{L} \times \Delta t_{R}+m_{R} \times \Delta t_{L}}{\Delta t_{R}+\Delta t_{L}}
\end{aligned}
$$

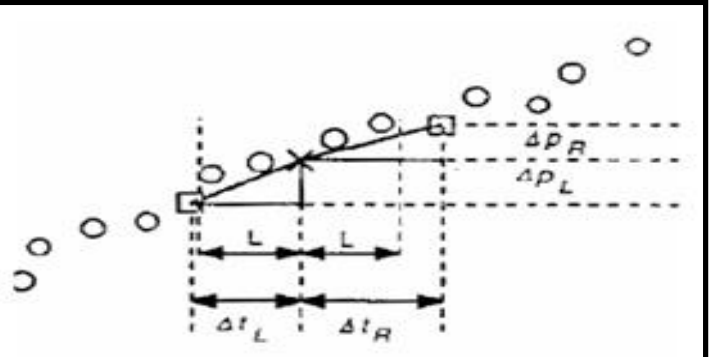

- DATA PONTS

$X$ = PONT TO BE DEATEO

D PONTS USED FOR THE CALCULATION

$m_{p}=$ VALUE of DeravatTVE

Figure 3: Five-point method for calculating the pressure derivative [4]

\subsubsection{Determination of the pressure Derivative by MS Excel:}

1- Plot $\Delta \mathrm{p}$ vs $\Delta \mathrm{t}$ on the log-log paper and then plot $\Delta \mathrm{p}^{`}$ vs $\Delta \mathrm{t}$ in the same graph, where can be calculated $\Delta \mathrm{P}^{\prime}$ from these equations:

$$
\begin{gathered}
m_{L}=\frac{\Delta p_{L}}{\Delta t_{L}} \\
m_{L}=\frac{\Delta p_{R}}{\Delta t_{R}}
\end{gathered}
$$




$$
\Delta p^{\prime}=\frac{m_{L} \Delta t_{R}+m_{R} \Delta t_{L}}{\Delta t_{R}+\Delta t_{L}} \times \Delta t
$$

Where:

$\mathrm{m}_{\mathrm{L}}=$ Value of derivative in pressure derivative smoothing algorithm in left side,

$$
\mathrm{psi} / \mathrm{h} \text {. }
$$

$\mathrm{m}_{\mathrm{R}}=$ Value of derivative in pressure derivative smoothing algorithm in right side,

$$
\text { psi/h. }
$$

$\Delta \mathrm{p}^{`}=$ Pressure derivative, $\mathrm{psi} / \mathrm{h}$.

$\Delta \mathrm{p}_{\mathrm{L}}=$ Additional pressure change owing to presence of no flow boundary in left side, psi.

$\Delta \mathrm{p}_{\mathrm{R}}=$ Pressure change in pressure derivative smoothing algorithm in right side, psi.

$\Delta \mathrm{t}_{\mathrm{L}}=$ Time change in pressure derivative smoothing algorithm in left side, $\mathrm{h}$.

$\Delta \mathrm{t}_{\mathrm{R}}=$ Time change in pressure derivative smoothing algorithm in right side, $\mathrm{h}$.

2- Estimate the formation permeability (k), skin factor (S) using the following relationship:

$$
\begin{aligned}
\mathrm{k} & =\frac{70.65 \mathrm{q} \mu \mathrm{B}}{\mathrm{m} \mathrm{h}} \ldots \ldots \ldots \ldots \ldots \ldots \ldots \ldots \ldots \ldots \ldots \ldots \ldots \ldots \ldots \ldots \ldots \ldots \ldots \ldots \ldots \ldots \ldots \ldots \ldots \ldots \ldots \\
\mathrm{S} & =1.151\left(\frac{(\Delta \mathrm{P})_{\mathrm{S}}}{2.303 \mathrm{~m}^{\prime}}-\log \left(\frac{\mathrm{K}(\Delta \mathrm{t})_{\mathrm{S}}}{\varphi \mu \mathrm{C}_{\mathrm{t}} \mathrm{r}_{\mathrm{w}}^{2}}\right)+3.227\right)
\end{aligned}
$$

Where:

$(\Delta \mathrm{p})_{\mathrm{s}}=$ Pressure change coordinate during the infinite acting period, psi $(\Delta \mathrm{t})_{\mathrm{s}}=$ Time coordinate of a point during the infinite acting period, $\mathrm{h}$.

\subsection{Pressure Transient Software (PT4.0)}

PT4.0 is one of the programs which used to analysis data that are obtained from drawdown and build-up tests. PT4.0 (Pressure transient (version.4)) is a full-featured system for evaluating pressure transient well tests. Using a standard Windows user interface, it implements most classical and log-log type curve methods, as well as an advanced "Adjust and Compare" technique to interactively interpret test data.

Proceedings of First Conference for Engineering Sciences and Technology (CEST-2018), vol. 1 
Pressure Transient Analysis by Using MS. Excel Sheet and Computer Programming

\section{Calculations and Results}

To illustrate the procedure, it is shown here the analysis of data of well. by using MS Excel sheet and PT4.0 software. Figure 3 shows plot of $\Delta \mathrm{p}\left(\mathrm{P}_{\mathrm{ws}}-\mathrm{P}_{\mathrm{wf}}\right)$ versus $\Delta \mathrm{t}$ on $\log$-log plot., Figure 4 represents Horner semilog plot. The best straight line of first slope was found as shown in Figure 5. Figure 6 shows Horner semilog plot by using PT4.0 software MS Excel sheet was used to plot the derivative curve on $\log$-log plot with the plot of $\left(\mathrm{P}_{\mathrm{ws}}-\mathrm{P}_{\mathrm{wf}}\right)$ versus $\Delta \mathrm{t}$ as shown in Figure 7. Figure 8 shows the plotting of Derivative curve by using PT4.0 software. Permeability of the formation and the skin factor were calculated as was described in previous sections. Results of analysis data of well are shown in Table 2.

Table 2: Results of analyzing data of the well

\begin{tabular}{|r|c|c|c|c|}
\hline \multirow{2}{*}{ Property } & \multicolumn{2}{|c|}{ Excel Sheet } & \multicolumn{2}{c|}{ PT4.0 Program } \\
\cline { 2 - 5 } & Horner & Derivative & Horner & Derivative \\
\hline $\mathrm{P}^{*}(\mathrm{psi})$ & 4041 & - & 4043.8 & - \\
\hline $\mathrm{m}(\mathrm{psi} / \mathrm{cycle})$ & 90.486 & - & 92.68 & - \\
\hline $\mathrm{K}(\mathrm{md})$ & 135.568 & 171.93 & 132.321 & 109.13 \\
\hline $\mathrm{Kh},(\mathrm{md} . \mathrm{ft})$ & 6202.24 & 7865.8 & 6053.68 & 4993 \\
\hline $\mathrm{S}$ & 1.138 & 3.055 & 0.96997 & -0.308 \\
\hline
\end{tabular}

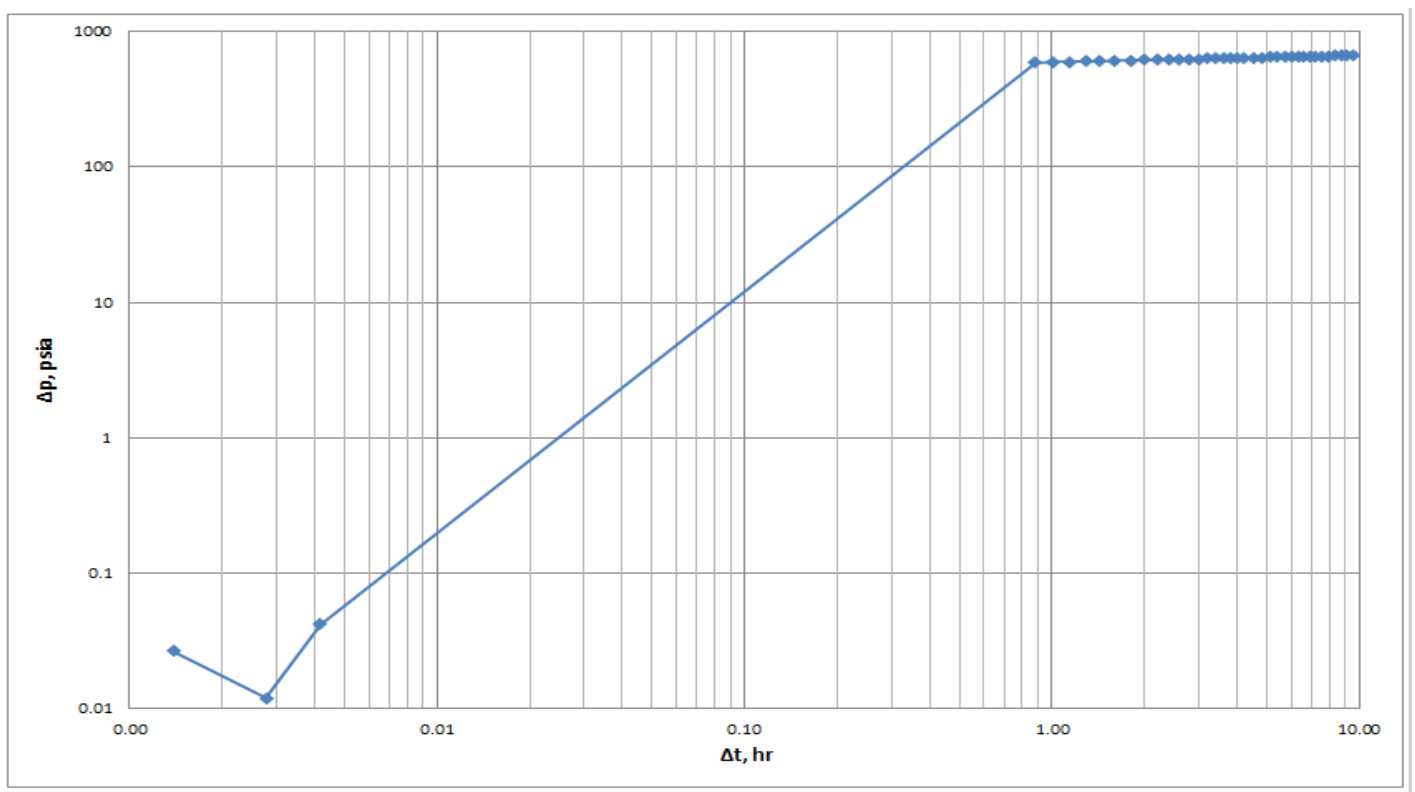

Figure 3: $\Delta p$ (Pws-Pwf) versus $\Delta t$ on $\log -\log$ plot 
Tabar et al., CEST-2018, AIJR Proceedings 2, pp.310-322, 2018

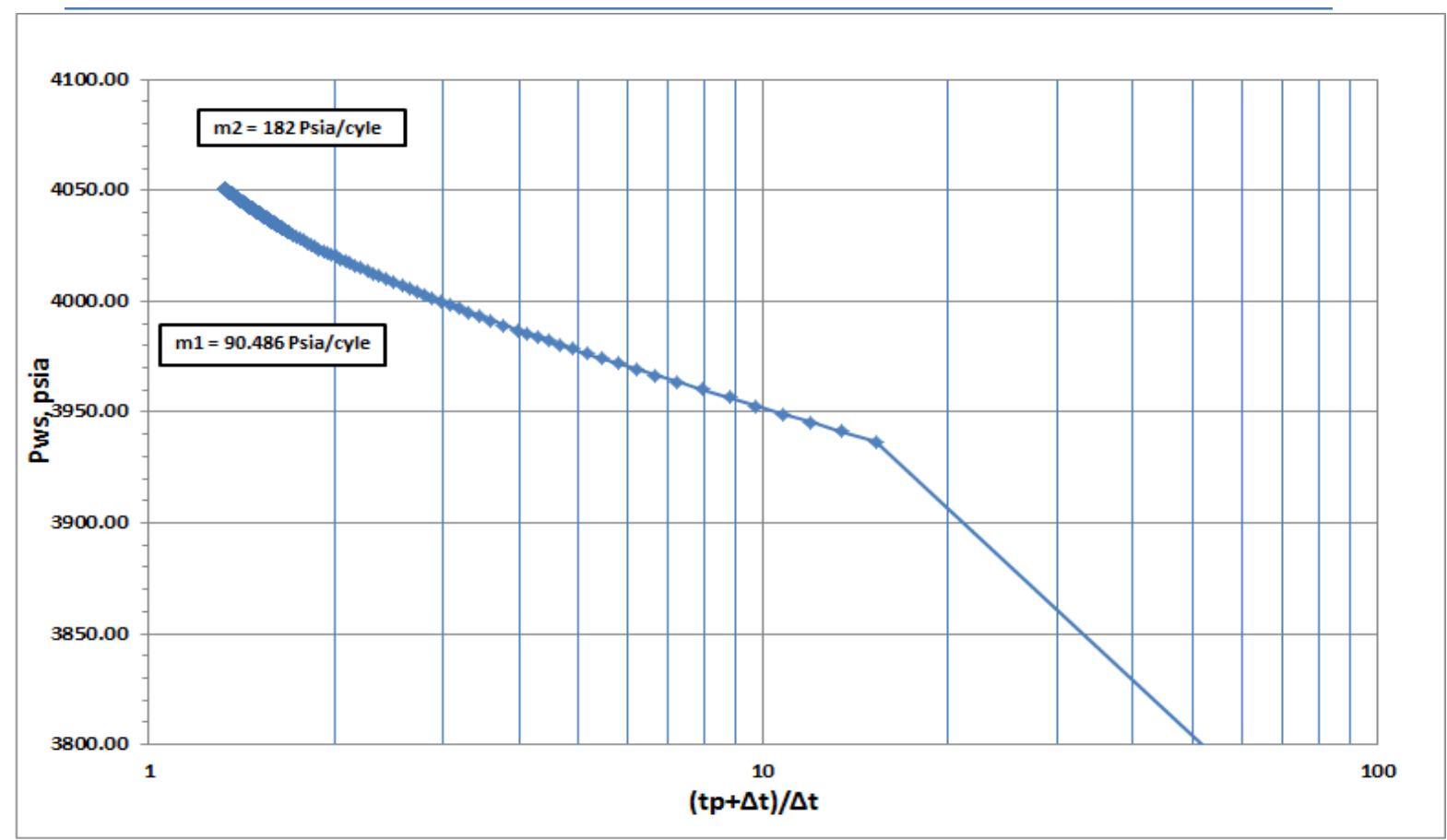

Figure 4: Horner plot of the well by using MS Excel software

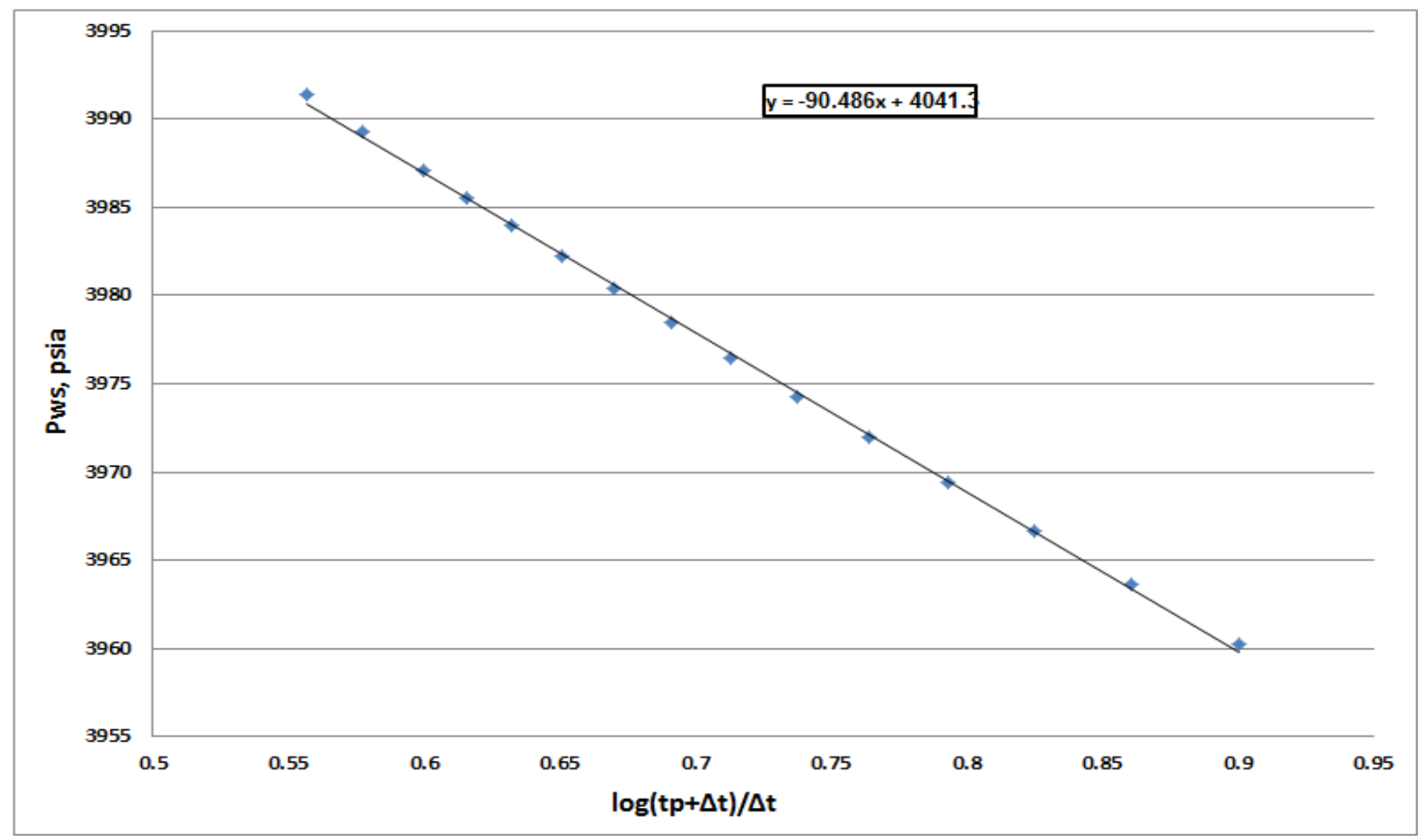

Figure 5: MTR straight line of Horner Plot

Proceedings of First Conference for Engineering Sciences and Technology (CEST-2018), vol. 1 319 
Pressure Transient Analysis by Using MS. Excel Sheet and Computer Programming

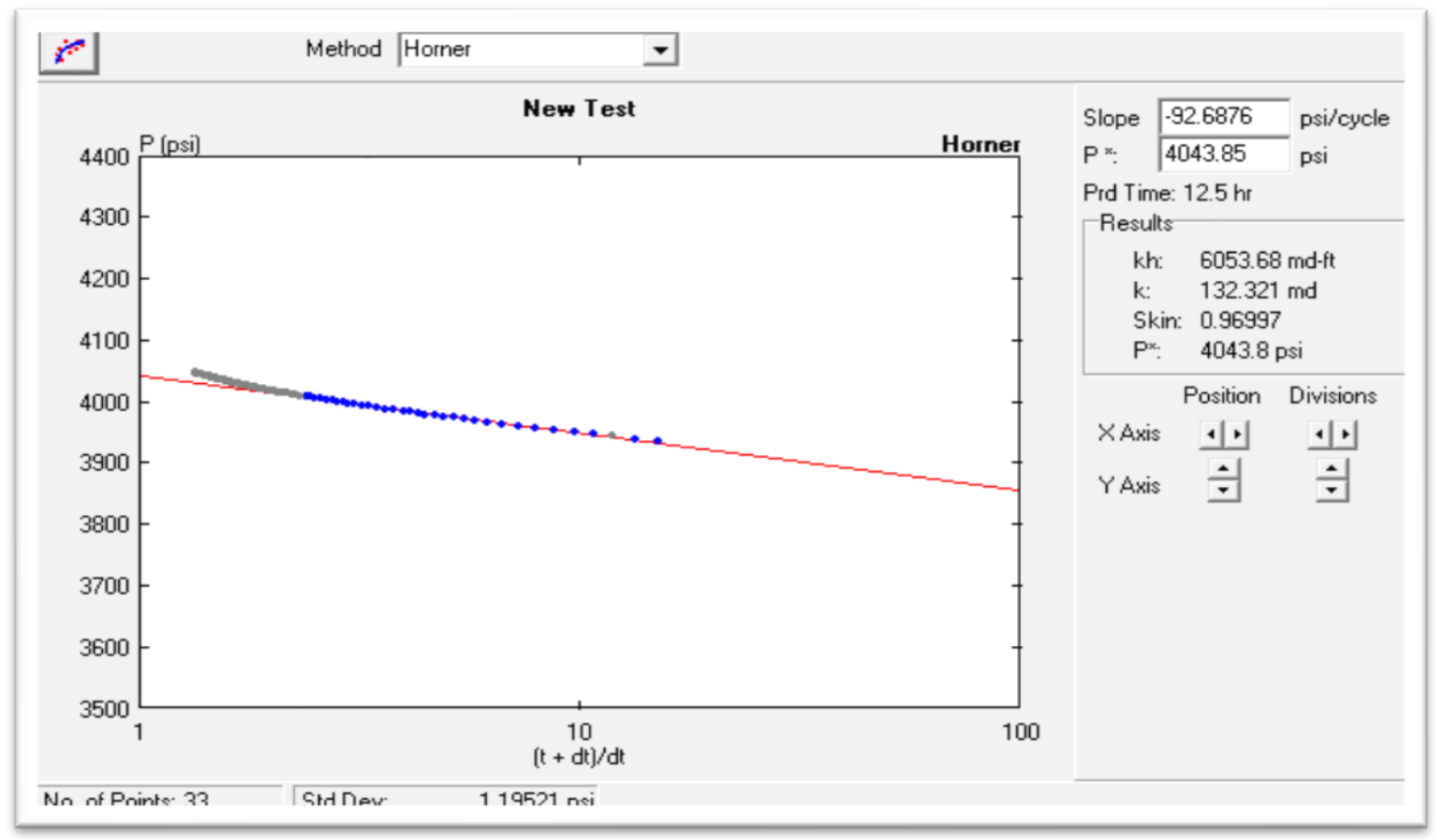

Figure 6: Horner plot for the well by using (PT4.0) software.

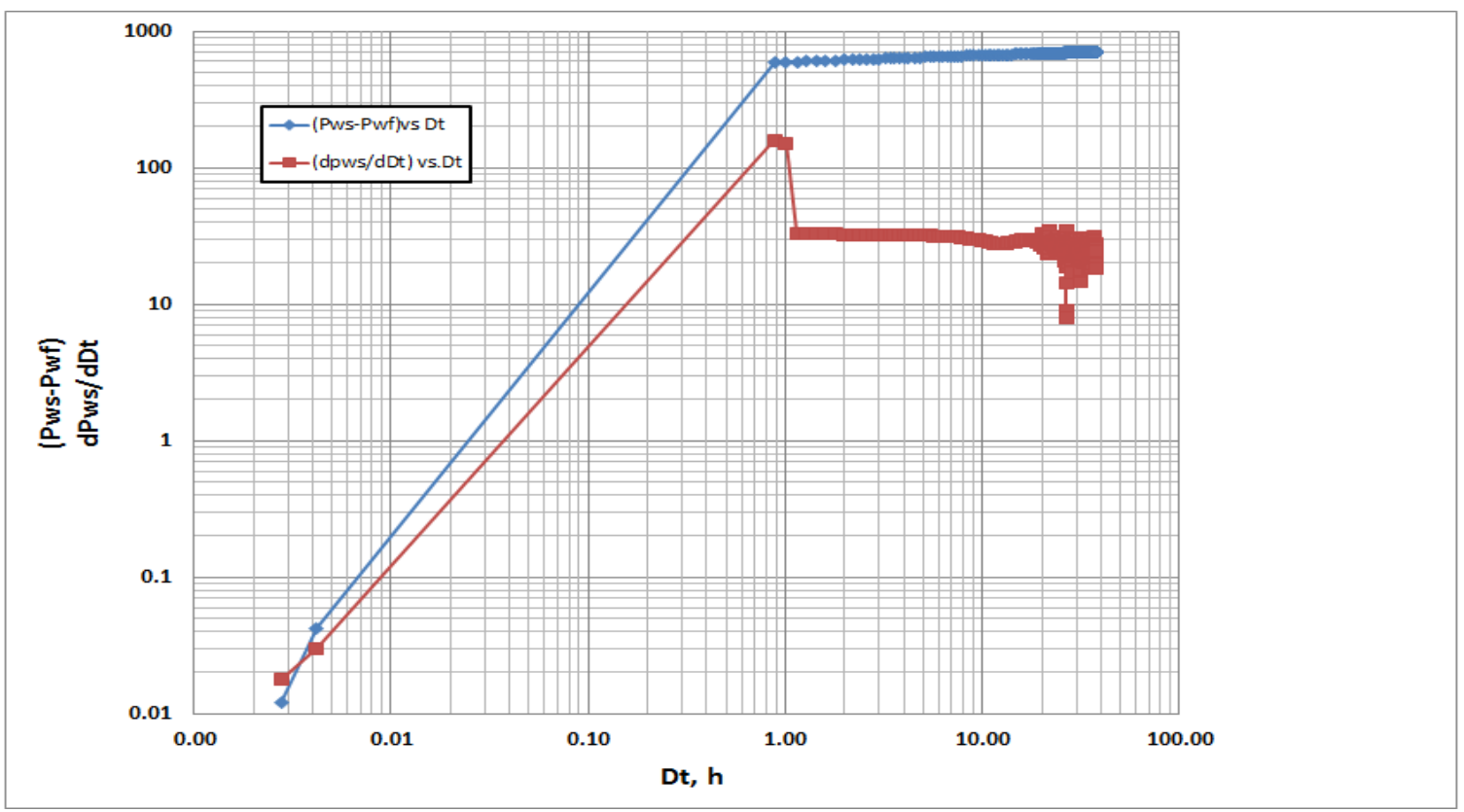

Figure 7: Derivative plot of the well by using MS Excel software 


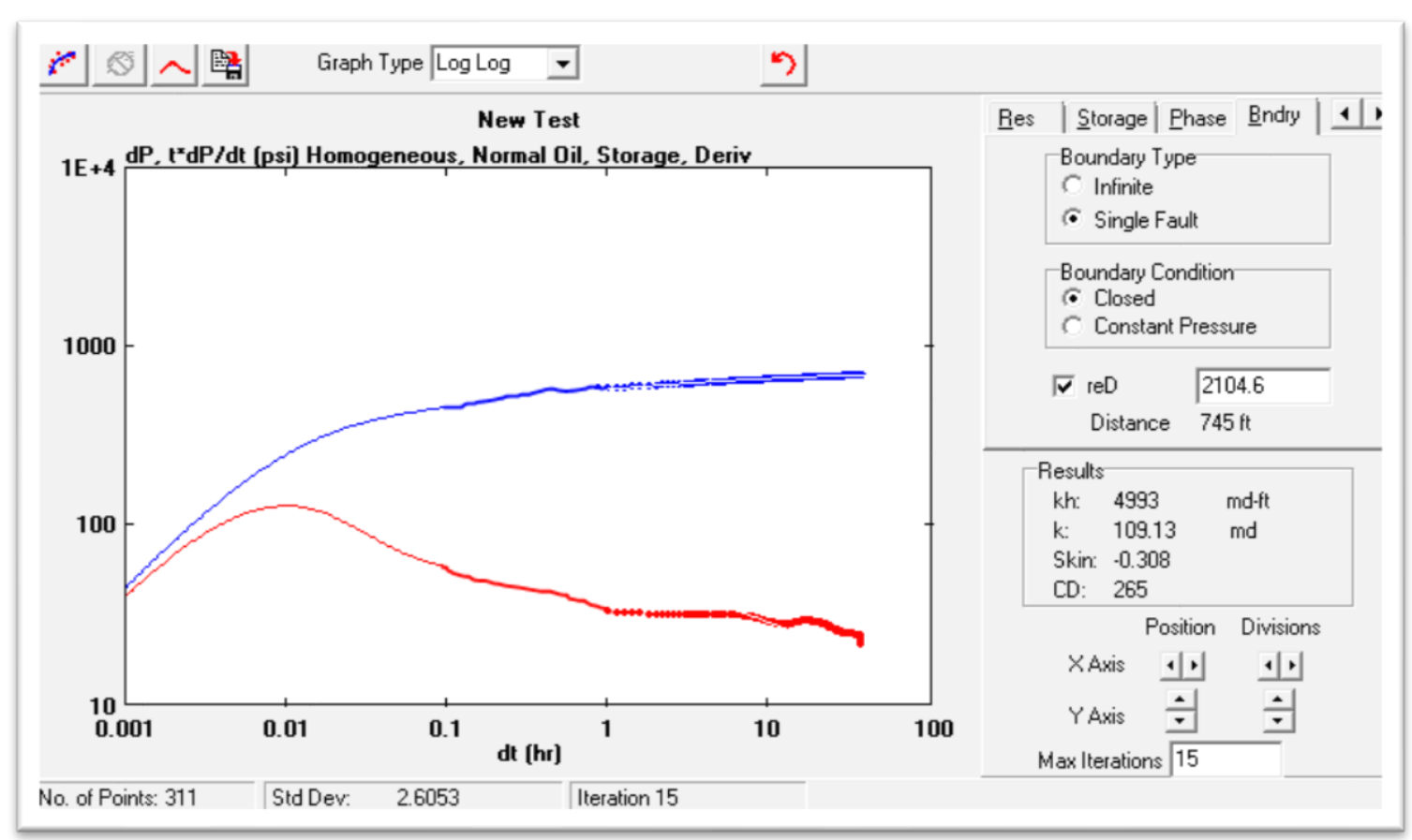

Figure 8: Derivative plot for the well by using (PT4.0) software.

\section{Discussion}

The paper presents a two programs that used to evaluate the pressure build up test for the well from Libyan field. MS Excel sheet and PT4.0 software were using to characterize the well, as well as estimation of formation permeability, skin factor and reservoir pressure. As shown for studied case, using of the pressure Horner curve was principle to identify the MTR of the test and to characterize the condition at the reservoir boundary. The Horner plots for both programs in Figure 4 and Figure 6 show that sealing fault has appeared by two slopes. Otherwise, the derivative curve was also used to identify the MTR and to evaluate the reservoir condition and the sealing fault has not appeared clearly because the period of buildup test (37hrs) was small as shown in Figure 7 and 8. Table 2 shows the results of Horner and derivative methods by using both programs MS Excel and PT4.0 software. As the results, formation permeability by both programs are agree to each other and reservoir pressure as well. The skin factor of the well indicates that the zone around the well has small damage by using Horner plot for both programs while derivative plot gives positive value of skin factor

Proceedings of First Conference for Engineering Sciences and Technology (CEST-2018), vol. 1 
Pressure Transient Analysis by Using MS. Excel Sheet and Computer Programming

by using MS Excel and negative value by using PT4.0 software. According to the results of the studied case which indicate that Horner method is the more accurate than derivative methods.

\section{Conclusion}

This paper presents a simple procedure to analyze the pressure buildup test using MS Exel and PT4.0 software. Sealing fault was appeared clearly in Horner plot by two slopes whereas derivative plot, the second slope was not presented clearly. Horner plot of MS Excel software gives appreciate results to PT4.0. whereas the derivative method gives not that much different results between both of programs. Results of the studied case indicates that Horner method is more accurate than method of direct derivative method. For the future, hopefully, there will be more cooperation between oil and gas governmental/international companies and PE in Sirte University, therefore to provide us the commercial petroleum simulators to develop models according to field data which help us to increase the knowledge of academic research and develop the student in academic and field study. Hence, using directly the modern programs in well testing will save time and provides reliable parameter values.

\section{References:}

[1] D. Bourdet, T. M. Whittle, A A Douglas, and Y. M. Pirard: "A new Set of Type Curves Simplifies Well Test Analysis," World Oil, May 1983, pp95

[2] R. C . Earlougher, "Advances in Well Test Analysis," Society of Petroleum Engineers, Dallas, TX, 1977.

[3] D. R. Horner, "Pressure Buildup in Wells" Proceedings of Third World Petroleum Congress, E. J. Brill, Leiden, November 1951, p503.

[4] J. Lee, and R. A. Wattenbarger, "Gas Reservoir Engineering”, SPE Textbook Series vol. 5, TX:, (1996). 